\title{
Lysogeny in Proteus rettgeri and the Host-Range of $P$. rettgeri and $P$. hauseri Bacteriophages
}

\author{
By J. N. COETZEE \\ Department of Microbiology, University of Pretoria, Pretoria, South Africa
}

(Received 3 September 1962)

\section{SUMMARY}

Twenty-two different phage-types of Proteus rettgeri were investigated for lysogeny by growing strains singly, in mixtures and by ultraviolet induction. Five of the strains were lysogenic for other members of the group. The phages differed from one another in host-ranges. Eighteen different lytic phages were isolated from sewage with action on one or more of the strains. The host-range of all 23 phages was tested against a number of $\boldsymbol{P}$. hauseri, $\boldsymbol{P}$. morganii, Providence and other intestinal organisms. Twelve of the phages had productive cycles of infection on 24 strains of $P$. hauseri; 21 of the phages attacked 19 Providence strains. Two of the phages lysed the same 2 out of 40 strains of Escherichia coli. The efficiencies of plating varied from $10^{-4}$ to unity. No action was demonstrated on any of the $\boldsymbol{P}$. morganii or other strains tested. The host-range of $23 \boldsymbol{P}$. hauseri phages previously isolated from sewage and from lysogenic $P$. hauseri was tested against $\boldsymbol{P}$. rettgeri, $\boldsymbol{P}$. morganii and Providence strains. Three Providence and $2 \boldsymbol{P}$. morganii strains proved susceptible to productive infection by a number of the $\boldsymbol{P}$. hauseri phages; $15 \boldsymbol{P}$. rettgeri strains were lysed by one or more of $18 P$. hauseri phages. Some of the $P$. hauseri phages also caused abortive infection associated with cell death in some $\boldsymbol{P}$. morganii and $\boldsymbol{P}$. rettgeri organisms. The results indicate close ties between the $\boldsymbol{P}$. hauseri and $\boldsymbol{P}$. rettgeri groups, and between $\boldsymbol{P}$. rettgeri and the Providence strains.

\section{INTRODUCTION}

Differences of opinion exist whether organisms of the Proteus rettgeri and $\boldsymbol{P}$. morganii groups should be included with $\boldsymbol{P}$. hauseri in the genus Proteus. Kauffmann (1951) suggested combining $\boldsymbol{P}$. rettgeri and $\boldsymbol{P}$. morganii strains in one group. Topley $\&$ Wilson's Principles (1955) included $\boldsymbol{P}$. morganii strains in the Proteus group but considered $\boldsymbol{P}$. rettgeri strains to be more closely related to paracolon organisms and proposed the name 'Bacterium rettgeri' for them. On the basis of the guanidine+ cytosine content of their deoxyribonucleic acids Falkow, Ryman \& Washington (1962) showed that $\boldsymbol{P}$. morganii strains were distinct from $\boldsymbol{P}$. hauseri, $\boldsymbol{P}$. rettgeri and Providence strains. The latter three organisms possess very similar base compositions. The taxonomic relationships of the Providence group is also uncertain. Kauffmann (1951) described Providence strains as intermediate between Shigella and Proteus. The latter author as well as Ewing, Tanner \& Dennard (1954) stressed the biochemical relationships between Providence, $\boldsymbol{P}$. rettgeri and $\boldsymbol{P}$. morganii. Topley \& Wilson's Principles (1955) relegated Providence strains to a subgroup of paracolon organisms. P. hauseri is certainly a well-defined group; it differs markedly 
in its biochemical reactions from other members of the Enterobacteriaceae (Topley \& Wilson, 1955) and only isolated instances of serological cross-reactions with other members of this family have been recorded (Kauffmann, 1951; Namioka \& Sakazaki, 1959). Bacteriophage reactions have confirmed the above findings. Phages of $P$. hauseri were tested by Brandis \& Schwarzrock (1956), Coetzee (1958) and Vieu (1958) for action on many strains of Escherichia coli, Salmonella, Shigella, Pseudomonas, Staphylococcus, and paracolons. Vieu also tested $P$. hauseri phages against a number of $\boldsymbol{P}$. morganii, $\boldsymbol{P}$. rettgeri and Providence strains. Apart from the finding by Vieu that an unspecified number of $\boldsymbol{P}$. hauseri phages produce 'incomplete lysis or some isolated plaques' on 2 of $18 P$. rettgeri strains no other positive results have been recorded. In examining the haemagglutinating activity of $\boldsymbol{P}$. rettgeri and $\boldsymbol{P}$. morganii strains (Coetzee, Pernet \& Theron, 1962) it was found that while $\boldsymbol{P}$. rettgeri strains differed from $\boldsymbol{P}$. hauseri and $\boldsymbol{P}$. morganii in the range of species of vertebrate red cells agglutinated the haemagglutinins of all thre groups shared the property of not being inhibited by mannose (Shedden, 1962). This finding and the observation by Vieu (1958) led us to investigate the bacteriophage relationships of $\boldsymbol{P}$. hauseri, $\boldsymbol{P}$. rettgeri, Providence and $\boldsymbol{P}$. morganii organisms.

\section{METHODS}

Organisms. Twenty-eight strains of Proteus hauseri were used. Nine were 'vulgaris' varieties and the remainder 'mirabilis' strains. They were isolated from human faeces or urine and all but four (nos. 108, 121, 171, 192) are hosts for a series of phages (Coetzee, 1958; Coetzee \& Sacks, 1960 a). Identifying numbers are given in Table 3. All the cultures were in the A morphological phase (Coetzee \& Sacks, $1960 b$ ) and when the swarms were matched on nutrient agar plates they all showed a narrow line of demarcation. This is taken to mean that the strains differ in some respect (Dienes, 1946; Krikler, 1953; Story, 1954). Fourteen locally isolated strains of $\boldsymbol{P}$. rettgeri and $8 \boldsymbol{P}$. rettgeri cultures obtained from the National Collection of Type Cultures (NCTC; Colindale, London) were used. Identifying numbers are given in Table 1 . The $\boldsymbol{P}$. morganii strains used comprised 6 NCTC strains and 11 locally isolated cultures. The identifying numbers are NCTC 1707, 2815, 2818, 5845, 7381, 10041, and local no. м2, м3, м21, м47, м49, м71, м86, м92, м232, м235, M336. Twenty-four different $\mathbf{O}$ serological groups of Providence strains were used; they were supplied by Miss Shona Wright (Bacteriology Department, University of Edinburgh). They are all NCTC cultures and their identifying numbers are given in Table 4. Five different phage-types of Salmonella typhosa, 23 other Salmonella serological varieties, 40 different isolates of Escherichia coli, 8 different isolates of paracolon organisms, 8 Shigella strains and 7 strains of Pseudomonas aeruginosa were used in host-range experiments. Cultures were stored on agar slopes at $4^{\circ}$.

Phages. The 23 Proteus hauseri phages used are listed in Table 2. Twenty-one were isolated from sewage (Coetzee, 1958), the remaining two are virulent clear plaque mutants of temperate phages 34/13 and 12/57 (Coetzee \& Sacks, 1960a, $c$ ). Twenty-three $\boldsymbol{P}$. rettger $i$ phages were isolated during the present work from sewage and from lysogenic strains. The sewage isolations were by the enrichment technique of Adams (1959). Lysogeny was tested for by examining the supernatants of 
10-day-old broth cultures of single organisms and mixtures of organisms for phage ultraviolet irradiation of cultures was also used. These three methods of induction have been described (Coetzee \& Sacks, 1959, 1960a). All the $\boldsymbol{P}$. rettger $i$ strains were used as possible indicators. Phages isolated from sewage are identified by the number of the original indicator organism. Temperate phages are identified by fractions: the number of the lysogenic strain is the nominator and that of the indicator strain the denominator. The $\boldsymbol{P}$. rettgeri phages are listed in Table 1.

The nutrient agar and general methods used were those of Adams (1959); the broth was as described by Coetzee \& Sacks $(1960 b)$. Phages were purified by three successive single-plaque propagations on the host organism. Broth lysates were shaken with $0 \cdot 1$ vol. chloroform to kill bacteria, decanted to remove excess chloroform and aerated for about $30 \mathrm{~min}$. at $45^{\circ}$ to remove residual chloroform. Lysates were stored at $4^{\circ}$ in sterile containers. The host ranges of the phages were determined by spotting drops of phage suspensions on agar plates which had been layered with soft agar seeded with enough test organism to give a lawn. The phage suspensions contained about $10^{8}$ plaque-forming particles/ml. Plates were incubated at $37^{\circ}$ overnight before reading. Phages which showed reactions were then titrated simultaneously on the original host organism and on the new strains and the relative efficiency of plating (e.o.p.) calculated. Abortive infections were investigated by mixing phage and organism at a multiplicity of infection of about 1 at $37^{\circ}$. After an adsorption period of $5 \mathrm{~min}$. an aliquot was treated with chloroform and titrated for unadsorbed phage on the homologous host. Simultaneously another aliquot was titrated for viable bacteria and for total infective centres on both the organisms involved (Coetzee, De Klerk \& Sacks, 1960). Phages which had a low e.o.p. on heterologous hosts were investigated according to the above method using the homologous and heterologous organisms in separate experiments. These experiments were then repeated with the phage prepared on the heterologous host. In these experiments total infective centres were also assayed at the end of the latent periods (Bertani \& Weigle, 1953). In attempts to increase the e.o.p. or to convert abortive to productive infections the top-layer agar was enriched with $10 \mathrm{~g}$. vitamin-free pancreatic digest of casein/l. (Nutritional Biochemicals Corp., Cleveland, Ohio), 0.2 M-sodium chloride and ammonium phosphate, 0.01 M-calcium chloride and $0.01 \mathrm{~m}$-magnesium sulphate individually or together.

\section{RESULTS}

Demonstration of lysogeny in Proteus rettgeri. Five of the $\boldsymbol{P}$. rettgeri strains were lysogenic for one or more of the 22 strains of this group; phages were obtained by all three methods used. The intra-group host-range of these phages (Table 1) shows that they can be differentiated on their host-ranges. Taubeneck (1962) did not find lysogeny in $4 \boldsymbol{P}$. rettgeri strains he examined.

Isolation of Proteus rettgeri phages from sewage. Phages were isolated from sewage against 18 of the $\boldsymbol{P}$. rettger $i$ strains. The intra-group host-range (Table 1) shows that these phages can be distinguished on the basis of host-range and that the 22 hosts differ from one another in susceptibility to these phages. The e.o.p. of all the $\boldsymbol{P}$. rettgeri phages on heterologous $\boldsymbol{P}$. rettgeri hosts was unity.

Intra-group host-range of Proteus hauseri phages. The phages isolated on Proteus 


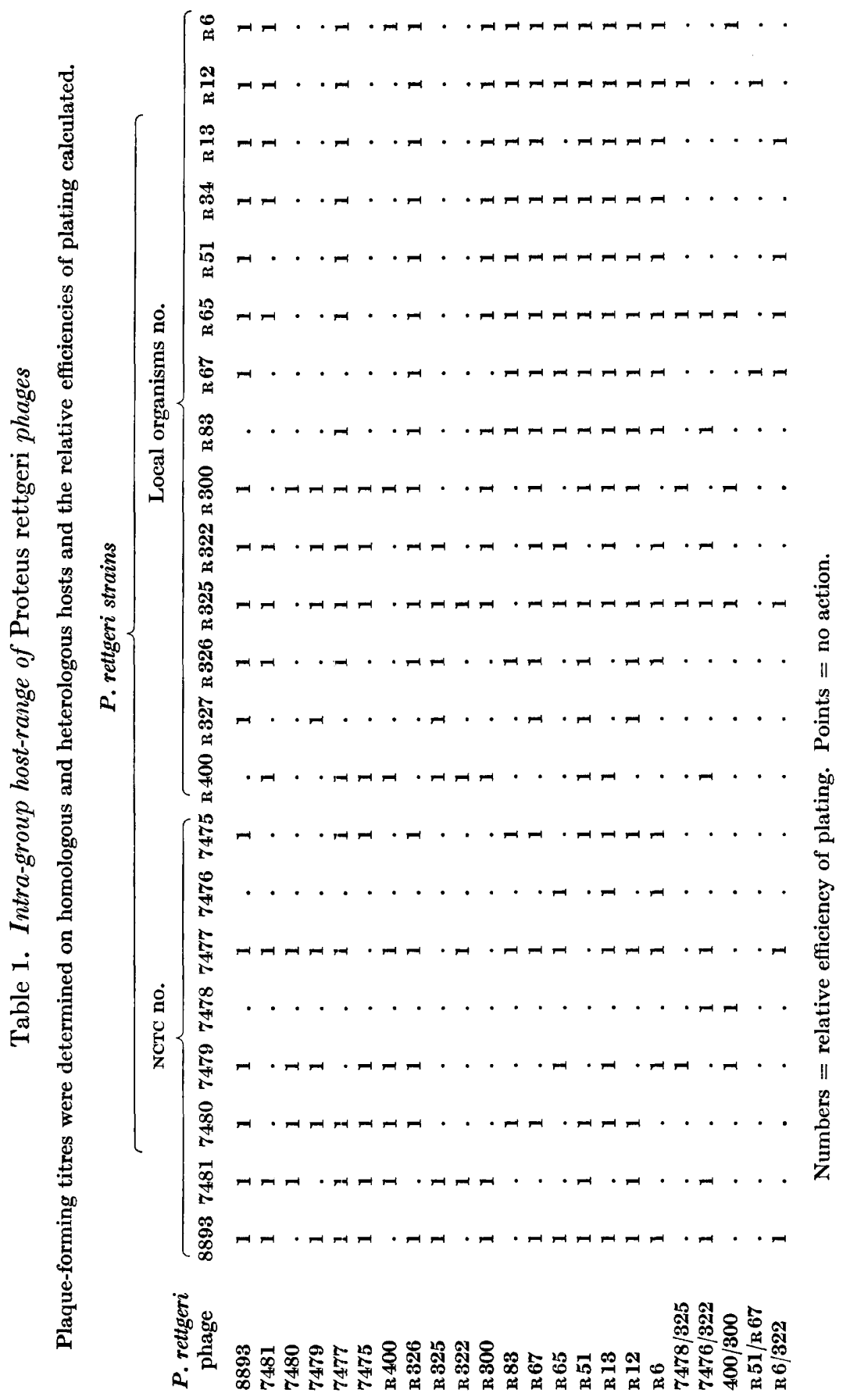




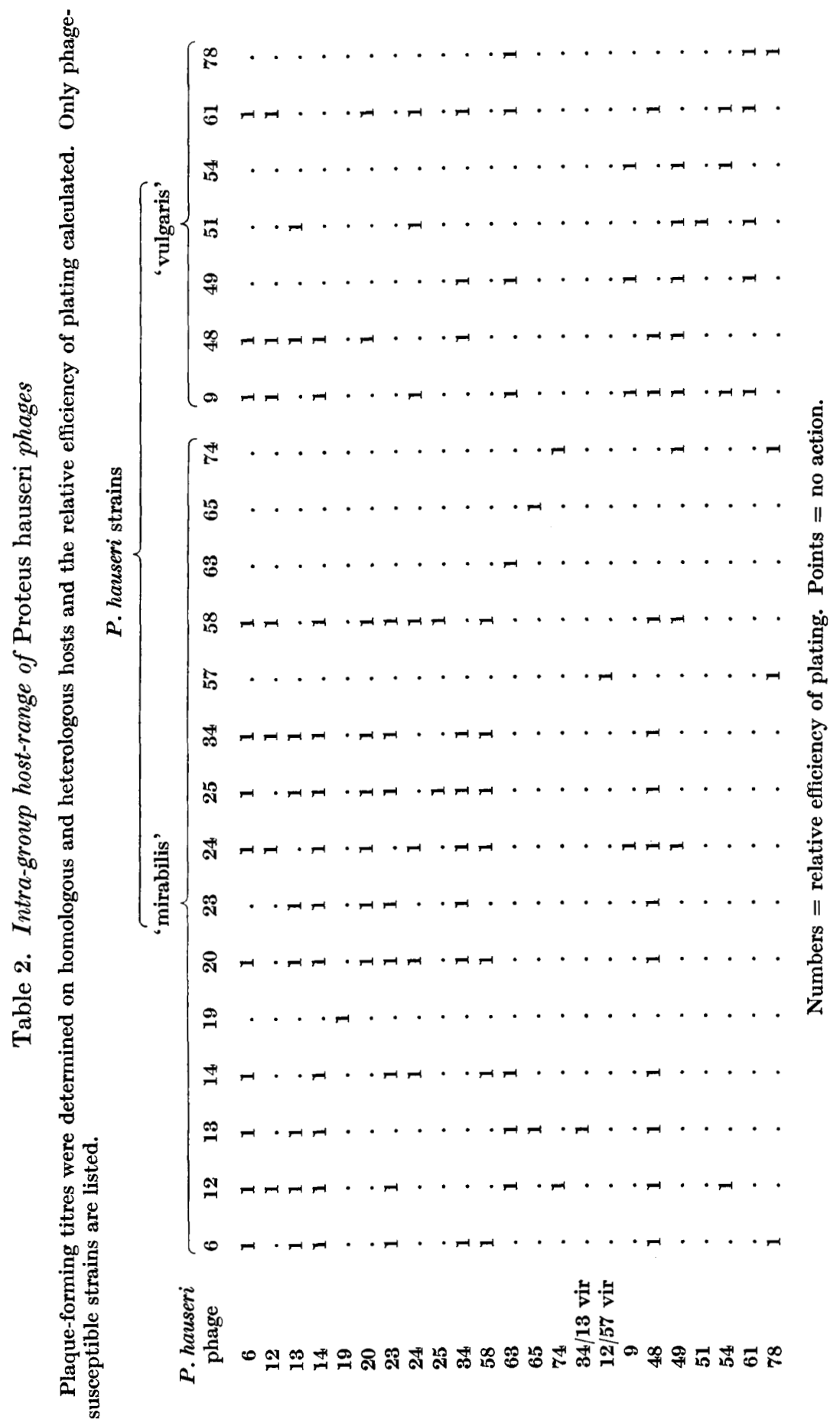




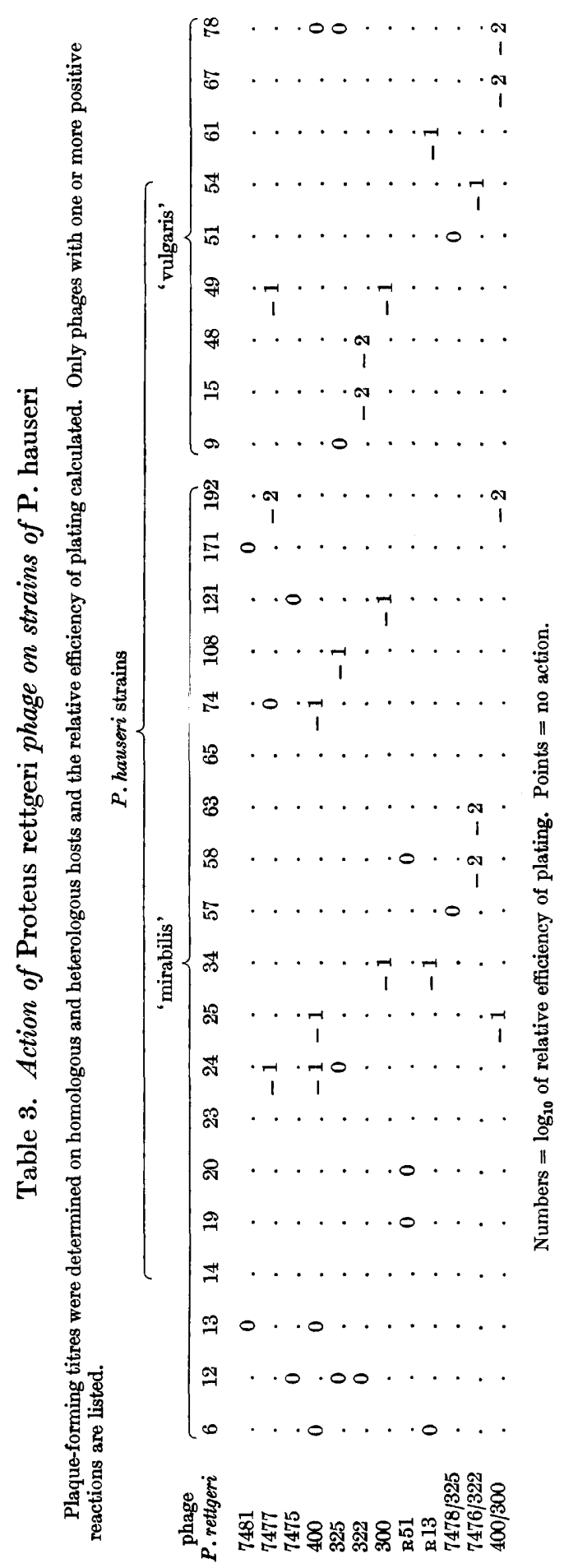




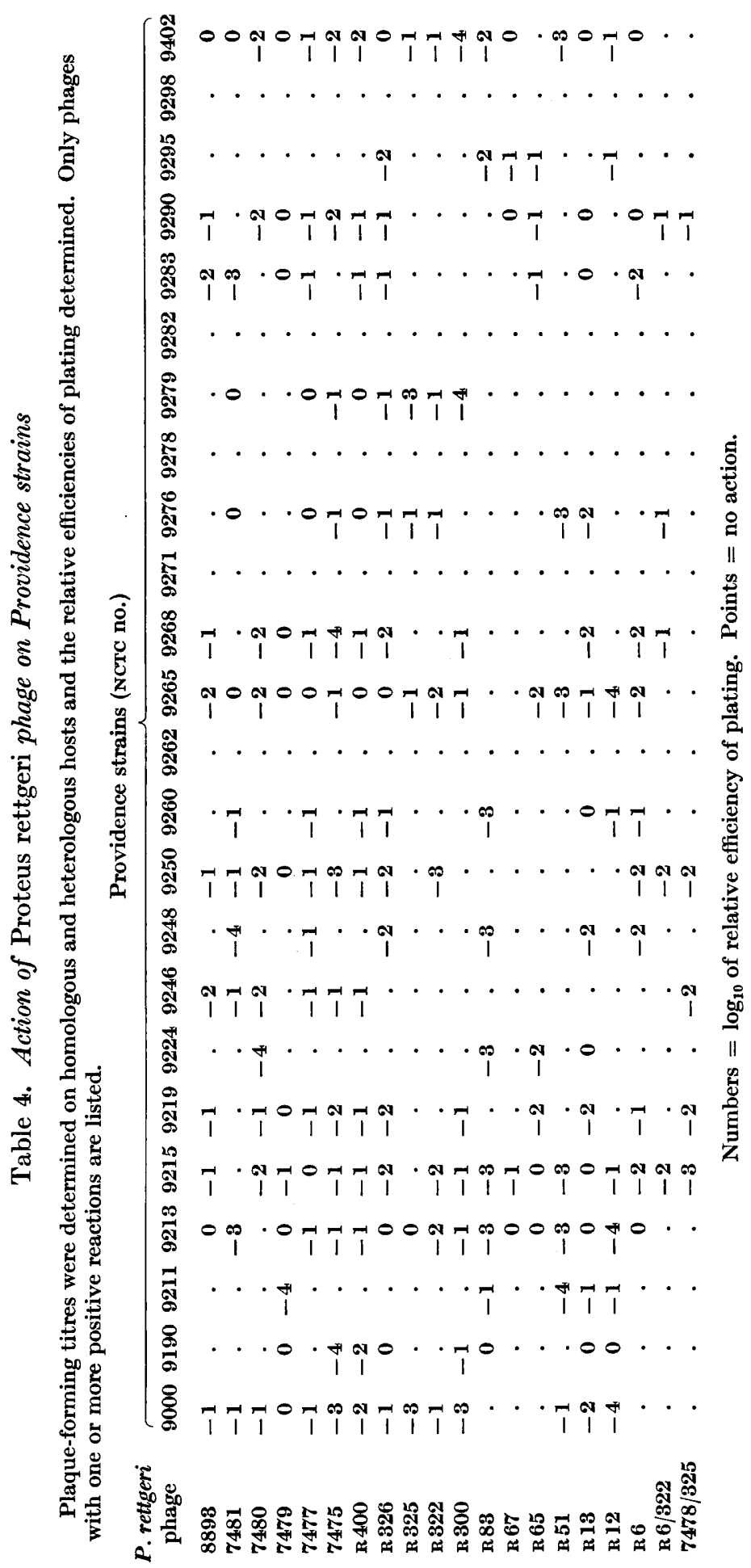


hauseri strains (Table 2) differed from one another in host-range and, as shown (Coetzee, 1958), many have the same e.o.p. on $P$. mirabilis and vulgaris varieties of $P$. hauseri.

Action of Proteus rettgeri phages on $\mathrm{P}$. hauseri organisms. Table 3 shows that 12 of the $\boldsymbol{P}$. rettgeri phages have productive cycles on several $\boldsymbol{P}$. hauseri hosts. The e.o.p. was often unity. A few of the systems with low e.o.p. were further examined. A typical example is the action of $P$. rettgeri phage 7477 on $P$. mirabilis strain 192. This phage has an e.o.p. of slightly less than $10^{-\mathbf{2}}$ on the 'mirabilis' strain, adsorbs equally well on both the organisms but kills few of the 'mirabilis' organisms. Phage prepared on strain 192 plates with equal efficiency on the two strains. However, a single cycle of growth in $\boldsymbol{P}$. rettgeri $\mathbf{7 4 7 7}$ is sufficient for it to revert to the original state with an e.o.p. of about $10^{-2}$ on $P$. mirabilis 192 . The efficiency of this transformation makes an explanation on grounds of host-range mutants untenable (Bertani \& Weigle, 1953) and suggests a phenotypic modification of the phage by the $\boldsymbol{P}$. rettgeri strain (Luria, 1953). Addition of casein digest or the various salts to the top-layer agar did not affect the e.o.p. The phenomenon was not further investigated.

Table 5. Action of Proteus hauseri phage on P. rettgeri strains

Plaque-forming titres determined on homologous and heterologous hosts and relative efficiencies of plating calculated. Only systems showing one or more positive reactions are presented.

P. rettgeri strains

\begin{tabular}{|c|c|c|c|c|c|c|c|c|c|c|c|c|c|c|c|}
\hline $\begin{array}{l}P . \text { hauseri } \\
\text { phage }\end{array}$ & $\begin{array}{l}\text { NCTC } \\
7481\end{array}$ & $\begin{array}{l}\text { NCTC } \\
7479\end{array}$ & R 400 & R 327 & R326 & R 325 & R 322 & R 300 & R 83 & R 67 & R 51 & R 34 & R13 & R 12 & R6 \\
\hline 6 & -1 & . & . & . & -1 & . & . & . & . & - & . & . & . & . & 0 \\
\hline 12 & -1 & . & . & . & -1 & . & $\mathbf{A}$ & . & $-\mathbf{3}$ & . & . & $\mathbf{A}$ & $\mathbf{A}$ & . & . \\
\hline 13 & -1 & . & • & . & -1 & . & . & . & - & . & -1 & - & -1 & . & . \\
\hline 14 & -1 & . & • & - & -1 & -3 & . & . & $-\mathbf{3}$ & . & . & • & . & $\mathbf{A}$ & . \\
\hline 19 & -1 & . & . & - & -1 & - & - & -2 & . & . & . & • & . & - & . \\
\hline 20 & -1 & . & -3 & . & -1 & $\mathbf{A}$ & . & . & . & -2 & . & - & . & . & . \\
\hline 23 & -1 & . & . & . & -1 & . & $\mathbf{A}$ & . & . & . & . & - & -2 & . & . \\
\hline 24 & -1 & . & . & -2 & -1 & . & . & . & -2 & - & . & -3 & . & $\mathbf{A}$ & . \\
\hline 25 & -1 & . & . & . & -1 & - & -3 & $-\mathbf{3}$ & $\mathbf{A}$ & . & . & . & . & . & -1 \\
\hline 34 & -1 & . & . & . & -1 & . & . & . & . & . & . & -1 & • & : & . \\
\hline 58 & -1 & . & . & . & -1 & $\mathbf{A}$ & . & . & . & . & . & . & . & $\mathbf{A}$ & . \\
\hline 63 & -1 & . & . & $-\mathbf{3}$ & -1 & . & . & . & . & . & -1 & - & -3 & . & . \\
\hline 74 & -1 & . & . & • & -1 & . & 0 & . & -2 & - & . & . & . & . & -1 \\
\hline $34 / 13$ vir & -1 & -1 & . & - & : & $\mathbf{A}$ & - & • & . & : & . & • & - & $\dot{0}$ & $\cdot$ \\
\hline 9 & -1 & - & . & - & -1 & - & - & - & - & -1 & . & - & - & -2 & - \\
\hline 48 & -1 & - & . & - & -1 & . & - & . & . & . & $\mathbf{A}$ & . & - & - & $\cdot$ \\
\hline 54 & -1 & - & -2 & . & -1 & - & 0 & - & . & . & . & . & . & : & . \\
\hline 61 & -1 & . & - & . & -1 & . & . & . & . & . & $\mathbf{A}$ & - & . & $\mathbf{A}$ & \\
\hline
\end{tabular}

Numbers $=\log _{10}$ of relative efficiency of plating. $A=$ abortive infection. Points = no action.

Action of Proteus rettgeri phage on $\mathbf{P}$. morganii organisms. No action of any kind was observed for $P$. rettgeri phages on the $17 P$. morganii strains used.

Action of Proteus rettgeri phage on other members of the family Enterobacteriaceae. The $P$. rettgeri phages did not have any action on any of the Salmonella, Shigella, paracolon or Pseudomonas strains tested. Phages isolated on $\boldsymbol{P}$. rettgeri strains R65 and NCTC 7477 plated with efficiencies of $10^{-2}$ on two strains of Escherichia coli 
(one strain locally isolated from faeces, the other a colicine $\mathbf{F}$ producing strain no. CA.42 supplied by Professor P. Fredericq, Liége, Belgium). The action of $\boldsymbol{P}$. rettgeri phages on 24 different Providence strains is recorded in Table 4; 20 of the phages acted on one or more of these 19 strains. The e.o.p. varied between $10^{-4}$ and unity. A few systems with low e.o.p. were further examined. Enrichment of the top-layer agar with casein digest or with the electrolytes used before did not affect the e.o.p. Phage which had passed through a Providence strain plated with equal efficiency on this strain and the particular P. rettgeri host. One cycle of growth in this latter strain re-established the original plating efficiency. The cases examined appeared to be examples of phenotypic modifications of the particular phages.

Table 6. Action of Proteus hauseri phage on P. morganii strains

Plaque-forming titres were determined on homologous and heterologous hosts and relative efficiencies of plating calculated. Only systems showing one or more positive results are presented.

\begin{tabular}{|c|c|c|c|c|c|c|}
\hline \multirow[b]{2}{*}{$\begin{array}{c}\text { P. hauseri } \\
\text { phages }\end{array}$} & \multicolumn{5}{|c|}{ P. morganii } & \\
\hline & $\begin{array}{r}\text { NCTC } \\
10041\end{array}$ & $\begin{array}{l}\text { NCTC } \\
2815\end{array}$ & м 235 & м 232 & M 47 & M21 \\
\hline 6 & -3 & . & . & • & 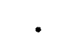 & . \\
\hline 12 & -3 & A & . & $\mathbf{A}$ & $\mathbf{A}$ & \\
\hline 14 & $-\mathbf{3}$ & $-\mathbf{3}$ & . & . & . & A \\
\hline 19 & $-\mathbf{3}$ & . & . & . & . & \\
\hline 24 & $-\mathbf{3}$ & A & . & . & . & A \\
\hline 34 & $-\mathbf{3}$ & . & 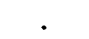 & . & $\mathbf{A}$ & $\mathbf{A}$ \\
\hline 48 & & 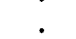 & A & . & . & . \\
\hline 63 & $-\mathbf{3}$ & $\mathbf{A}$ & . & . & . & . \\
\hline
\end{tabular}

Numbers $=\log _{10}$ of relative efficiency of plating. $\mathrm{A}=$ abortive infection. Points = no action.

Action of Proteus hauseri phages on P. rettgeri organisms. The e.o.p. of $\boldsymbol{P}$. hauseri phages on strains of $\boldsymbol{P}$. rettgeri is given in Table 5 . The original observation by Vieu (1958) that some $\boldsymbol{P}$. hauseri phages have an action on $\boldsymbol{P}$. rettgeri strains was confirmed and extended. Eighteen of the $\boldsymbol{P}$. hauseri phages caused productive infection in one or more of $15 P$. rettgeri strains. The e.o.p. of most of the phages on the new hosts varied between $10^{-1}$ and $10^{-3}$, but some plated with an efficiency of unity. Enrichment of the top-layer agar with amino acids or salts as before had no effect on the e.o.p. A few systems with low e.o.p. were further examined. A single passage through the heterologous host increased the e.o.p. to unity. The phenomenon was not further examined, it may be a phenotypic change like the cases previously mentioned. Discrepancies were sometimes observed in the host range of $P$. hauseri phages as determined by the spotting and titration techniques on $\boldsymbol{P}$. rettger $i$ hosts. In these instances an area of bacterial inhibition in the form of complete or partial clearing was present where the drop of phage was placed but the plaque-forming titre of the phage on the particular organism was zero. These cases were all due to abortive infection with killing of the adsorbing organism. No phage production was ever found (Coetzee et al. 1960; Amati, 1962). As with efforts to increase the e.o.p. the top-layer agar was enriched with the electrolytes and amino acids in attempts to convert abortive infections to productive ones but no difference in the course of adsorption could be demonstrated. 
Action of Proteus hauseri phage on P. morganii strains. Only organisms and phage which showed positive results are presented in Table $6 . P$. hauseri phage is decidedly less active on $\boldsymbol{P}$. morganii strains than on $\boldsymbol{P}$. rettgeri organisms. Only two $P$. morganii organisms (NCTC no. 10041, 2815) supported the productive cycle of one or more $P$. hauseri phages. The e.o.p. was $10^{-3}$ in all cases. The remaining positive reactions were all of the abortive infection variety associated with host killing. Vieu (1960) could not find any action by 33 temperate $P$. morganii phages on four strains of $\boldsymbol{P}$. hauseri. Taubeneck (1962), with a series of temperate $\boldsymbol{P}$. hauseri and $\boldsymbol{P}$. morganii phages, did not find any action of $\boldsymbol{P}$. morganii phage on $\boldsymbol{P}$. hauseri strains; his $\boldsymbol{P}$. hauseri phages also did not act on any $\boldsymbol{P}$. morganii strains.

Action of Proteus hauseri phage on Providence strains. Only three strains showed evidence of phage action: strain NCTC 9219 supported productive infection by phages 19 and 74, strain NCTC 9224 was similarly attacked by phages 12 and 48, and strain NCTC 9246 was productively lysed by phages $12 / 57$ vir, $6,9,12,13,14$, $23,24,48,51,58,67$. The e.o.p. varied between $10^{-2}$ and unity.

\section{DISCUSSION}

Organisms able to support the growth of a particular phage are considered to be closely related (Stocker, 1955) and the many examples of productive infection caused by Proteus hauseri phages on $\boldsymbol{P}$. rettgeri strains, and vice versa, should serve to strengthen the position of $\boldsymbol{P}$. rettger $i$ within the Proteus group and confirms the findings of Falkow et al. (1962). The finding of Falkow et al. of very similar guanidine + cytosine contents in the deoxyribonucleic acids of Providence, $P$. rettger $i$ and $\boldsymbol{P}$. hauseri strains may also reflect the finding that many $\boldsymbol{P}$. rettgeri phages productively infect Providence organisms. The relationship between Providence and $P$. hauseri strains, on the other hand, is possibly less close as judged by the small number of Providence strains susceptible to $P$. hauseri phages.

The productive infection of a few Proteus morganii hosts by $\boldsymbol{P}$. hauseri phage may also be regarded as evidence of a relation between these groups. That these interactions are not as frequent as those between $\boldsymbol{P}$. hauseri and $\boldsymbol{P}$. rettgeri strains and the fact that no $P$. rettgeri phage was found to attack $P$. morganii strains may support the finding of Falkow et al. (1962) that $P$. morganii strains are not as closely related to $\boldsymbol{P}$. hauseri as are $\boldsymbol{P}$. rettgeri organisms. The finding of two $\boldsymbol{P}$. rettgeri phages which caused productive infection in 2 of 40 strains of Escherichia coli was interesting. At present these reactions appear to be rare; perhaps more weight should be given to the other reactions encountered.

The abortive infections encountered mean at the very least that the strains have common phage receptors. No abortive infections were encountered in the nonProteus organisms tested and this adds to the significance of the finding.

The e.o.p. of phages on the heterologous hosts was often low but in all cases the phage progeny from the latter plated with the same efficiency on both the organisms involved. This investigation has shown close relationships between $P$. hauseri, $\boldsymbol{P}$. rettgeri, Providence and to a lesser extent $\boldsymbol{P}$. morganii strains which will have to be taken into account in any future taxonomic juggling with these organisms. 
Acknowledgement is made to Miss G. Pernet and Mrs C. J. Boshoff for technical assistance rendered. The author was in receipt of a grant from the South African Council for Scientific and Industrial Research.

\section{REFERENCES}

Adams, M. H. (1959). Bacteriophages. New York: Interscience Publishers, Inc.

Aмaт,, P. (1962). Abortive infection of Pseudomonas aeruginosa and Serratia marcescens with Coliphage P1. J. Bact. 83, 433.

Bertani, G. \& Weigle, J. J. (1953). Host controlled variation in bacterial viruses. $J$. Bact. 65, 113.

Brandis, H. \& Schwarzrock, A. (1956). Über Proteus-Bakteriophagen. Zbl. Bakt. (I. Orig.), 165, 226.

Coetzee, J. N. (1958). The characterization of a series of Proteus bacteriophages. S. Afr. J. lab. clin. Med. 4, 147.

Coetzee, J. N., De Klerk, H. C. \& Sacks, T. G. (1960). Host range of lactobacillus bacteriophages. Nature, Lond. 187, 348.

Coetzee, J. N., Pernet, G. \& Theron, J. J. (1962). Fimbriae and haemagglutinating properties in Proteus strains. Nature, Lond. 196, 497.

Coetzee, J. N. \& SACks, T. G. (1959). Lysogeny in the genus Proteus. Nature, Lond. 184, 1340.

Coetzee, J. N. \& Sacks, T. G. (1960a). Lysogeny in the genus Proteus. 1. Incidence of lysogenic strains. S. Afr. J. Lab. clin. Med. 6, 123.

Coetzee, J. N. \& SAcks, T. G. (1960b). Morphological variants of Proteus hauseri. J. gen. Microbiol. 23, 209.

Coetzee, J. N. \& Sacks, T. G. (1960c). Transduction of Streptomycin resistance in Proteus mirabilis. J. gen. Microbiol. 23, 445.

Dienes, L. (1946). Reproductive processes in 1 roteus cultures. Proc. Soc. exp. Biol., N.Y. 63, 265.

Ewing, W. H., Tanner, K. E. \& Dennard, D. A. (1954). The Providence group: an intermediate group of enteric bacteria. J. infect. Dis. 94, 134.

Falkow, S., Ryman, I. R. \& Washington, O. (1962). Deoxyribonucleic acid base composition of Proteus and Providence organisms. J. Bact. 83, 1318.

KaufFmann, F. (1951). Enterobacteriaceae, 1st ed. Copenhagen: Munksgaard.

Krikler, M. S. (1953). The Serology of Proteus vulgaris. Ph.D. Thesis: University of London.

LURIA, S. E. (1953). Host-induced modifications of viruses. Cold Spr. Harb. Symp. quant. Biol. 18, 237.

Namioka, S. \& Sakazaki, R. (1959). New K antigen (C antigen) possessed by Proteus and Rettgerella cultures. J. Bact. 78, 301.

ShedDen, W. I. H. (1962). Fimbriae and haemagglutinating activity in strains of Proteus hauseri. J. gen. Microbiol. 28, 1.

Stocker, B. A. D. (1955). Bacteriophage and bacterial classification. J. gen. Microbiol. $12,375$.

Story, P. (1954). Proteus infections in hospital. J. Path. Bact. 68, 55.

TAubeneck, U. (1962). Beobachtungen an lysogenen Proteus-stämmen. Zbl. Bakt. (I. Orig.), 185, 416.

Topley \& Wilson's Principles of Bacteriology and Immunity (1955). 4th ed. Ed. by G. S. Wilson and A. A. Miles. London: Edward Arnold.

VIEU, J. F. (1958). Note préliminaire sur la lysotypie de Proteus hauseri. Zbl. Bakt. (I. Orig.), 171, 612.

VIEU, J. F. (1960). Lysogénéité et sensibilité à la colicine $\mathrm{H}$ de Proteus morgani. Ann. Inst. Pasteur, 98, 769. 